This item was submitted to Loughborough's Research Repository by the author.

Items in Figshare are protected by copyright, with all rights reserved, unless otherwise indicated.

\title{
Stress induced by constrained sintering of 3YSZ films measured by substrate creep
}

PLEASE CITE THE PUBLISHED VERSION

http://onlinelibrary.wiley.com/doi/10.1111/j.1551-2916.2010.04160.x/abstract

PUBLISHER

Wiley (c) American Ceramic Society

VERSION

SMUR (Submitted Manuscript Under Review)

LICENCE

CC BY-NC-ND 4.0

\section{REPOSITORY RECORD}

Atkinson, Alan, Jung-Sik Kim, Robert A. Rudkin, Samuel Taub, and Xin Wang. 2012. "Stress Induced by Constrained Sintering of 3YSZ Films Measured by Substrate Creep". figshare.

https://hdl.handle.net/2134/11232. 
This item was submitted to Loughborough's Institutional Repository (https://dspace.lboro.ac.uk/) by the author and is made available under the following Creative Commons Licence conditions.

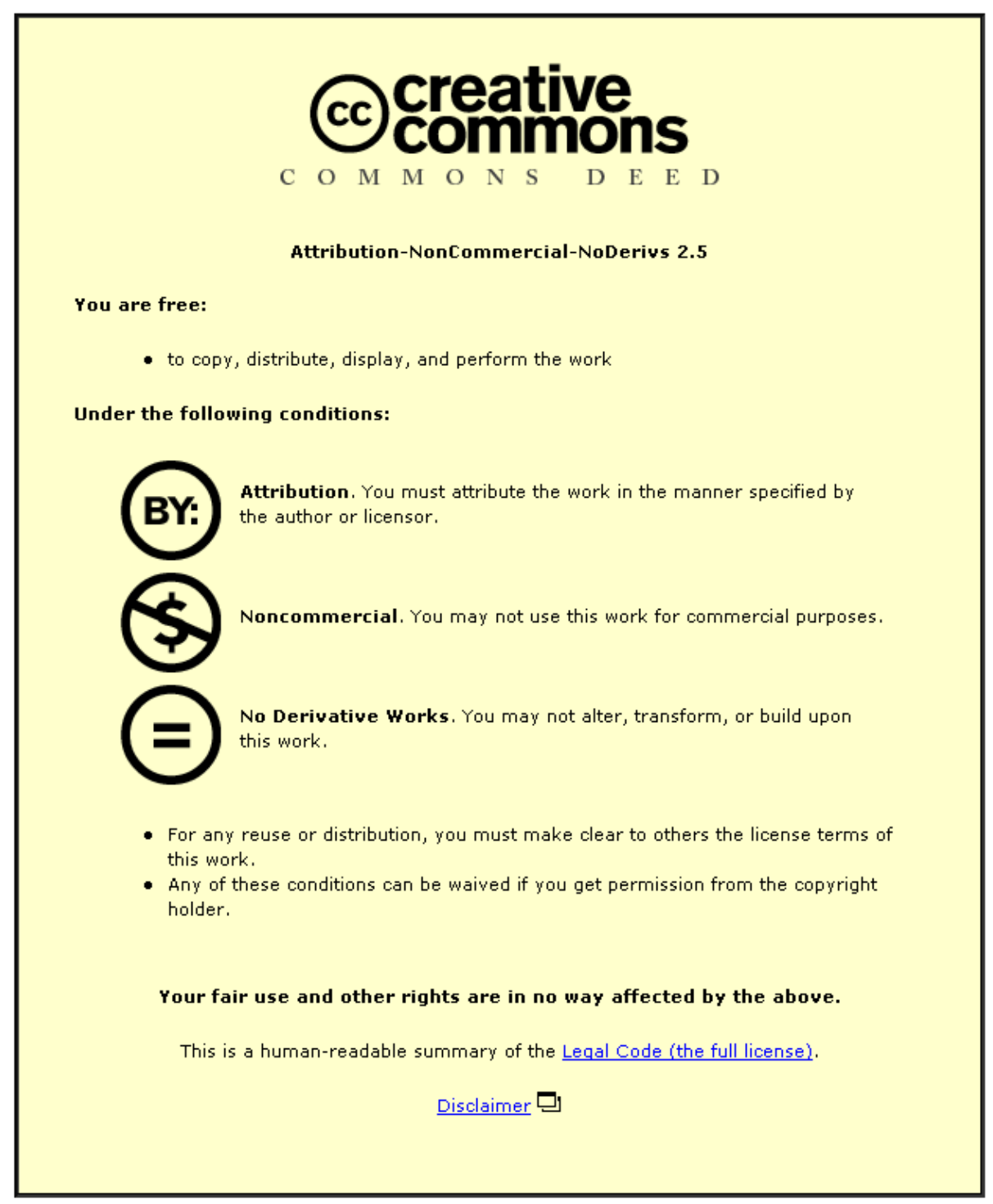

For the full text of this licence, please go to: http://creativecommons.org/licenses/by-nc-nd/2.5/ 


\section{journal}

\section{Stress induced by constrained sintering of 3YSZ films measured by substrate creep}

\begin{tabular}{|r|l|}
\hline Journal: & Journal of the American Ceramic Society \\
\hline Manuscript ID: & Draft \\
\hline Manuscript Type: & Article \\
\hline Author: & n/a \\
\hline Complete List of Authors: & $\begin{array}{l}\text { Atkinson, Alan; Imperial College, Materials } \\
\text { KIM, JUNG-SIK; Imperial College London, Materials } \\
\text { Rudkin, Robert; Imperial College London, Materials; Imperial } \\
\text { College, Materials } \\
\text { Taub, Samuel; Imperial College, Materials } \\
\text { Wang, Xin; Imperial College, Materials }\end{array}$ \\
\hline Keywords: & zirconia: yttria stabilized, sinter/sintering, stress, creep, fuel cells \\
\hline &
\end{tabular}

\section{scholarONE \\ Manuscript Central}




\title{
Stress induced by constrained sintering of 3 YSZ films measured by substrate creep
}

\author{
Alan Atkinson****, Jung-Sik Kim, Robert Rudkin, Samuel Taub and Xin Wang \\ Department of Materials, Imperial College, London SW7 2AZ, UK.
}

\begin{abstract}
3YSZ green layers approximately $10 \mu \mathrm{m}$ thick were screen printed onto 3 YSZ substrates up to $300 \mu \mathrm{m}$ in thickness. The stress induced by constrained sintering of the film (between $1150^{\circ} \mathrm{C}$ and $1350^{\circ} \mathrm{C}$ ) was measured by monitoring the bending displacement of vertical strips of bi-layers using a long-distance microscope. In order to deduce the stress it was first necessary to measure the creep properties of the substrates by monitoring the bending of horizontal beams under gravity.

The creep strain rate of the 3YSZ substrates was linearly dependent on applied stress at the low stresses and strains involved in the present work. The creep viscosity appeared to increase with strain (time), which might be due to changes in grain boundary composition, and had higher activation energy at temperatures above approximately $1250^{\circ} \mathrm{C}$. The magnitudes of the creep viscosities are in reasonable agreement with other creep data in the literature for 3 YSZ.

The in-plane stress induced during constrained sintering of the 3YSZ films had a maximum value of approximately $3 \mathrm{MPa}$ at $1200^{\circ} \mathrm{C}$. This behaviour is consistent with literature results reported for constrained sintering of bulk alumina. The stress induced by the constraint is of a similar order to the estimated sintering potential.
\end{abstract}

* Member, American Ceramic Society 
** Corresponding author

Department of Materials

Imperial College

London SW7 2AZ / United Kingdom

Tel.: +44 (0)207 5946809

The authors are grateful to colleagues at Rolls-Royce Fuel Cell Systems for helpful discussions and assistance with screen printing. This research was carried out as part of the UK EPSRC Supergen consortium project on "Fuel Cells: Powering a Greener Future". 


\section{Introduction}

Many planar solid oxide fuel cell (SOFC) concepts have a supported electrolyte with typical thickness in the range $5-20 \mu \mathrm{m}$ in order to reduce the ohmic resistance loss associated with the electrolyte. Anode-supported electrolytes are usually fabricated by co-sintering the electrolyte and the anode support. This imposes a constraint on the sintering of each component and leads to stress and distortion during the sintering process [1]. However, there is some common shrinkage in the plane of the composite and this relaxes the constraint somewhat. In other concepts (e.g. the integrated planar or segmented in series design of Rolls-Royce Fuel Cell Systems [2]) the substrate is effectively rigid. In such cases the film is fully constrained in its plane during sintering and shrinkage can occur only perpendicular to its plane (except within a distance of a few layer thicknesses of the film edges).

This constrained sintering process is also a feature of many other ceramic processing technologies and is a topic of considerable fundamental interest. The constraint results in a tensile stress in the plane of the film that is just sufficient to oppose its tendency to shrink in this plane, were it not for the constraint, and this has two main consequences. The first is that the densification is retarded [3,4], in comparison with an unconstrained case, and the second is that the in-plane tensile stress can cause crack-like defects and porous channels in the constrained film or delamination from the substrate [5,6]. Through-film defects are of particular concern in SOFC applications because, if they penetrate the electrolyte, fuel can then leak through the electrolyte and combust directly leading not only to loss of electrical efficiency, but also local hot-spots that can cause further mechanical damage.

Bang and Lu [7] measured the stress induced when borosilicate glass films were sintered on silicon substrates at $715^{\circ} \mathrm{C}$ and found very low values of approximately $20 \mathrm{kPa}$. In contrast Calata et al. [8] studied cordierite glass-ceramic films on silicon substrates at $900-1000^{\circ} \mathrm{C}$ and found a stress of approximately $0.2 \mathrm{MPa}$ before crystallisation rising to almost $1 \mathrm{MPa}$ 
after crystallisation. Choe et al. [9] also studied gold circuit paste sintering on silicon substrates and measured stresses of approximately $0.5 \mathrm{MPa}$ at $750^{\circ} \mathrm{C}$. Similarly Lin and Jean [10] measured the stress induced when silver circuit paste was sintered on a silicon substrate to be approximately $1 \mathrm{MPa}$ at $550-750^{\circ} \mathrm{C}$. In all these cases the substrate was silicon and deformed elastically in response to the induced stress and allowed the stress to be measured. The requirements for elastic deformation and chemical inertness of the substrate have limited these experiments to relatively low temperatures when compared with processing temperatures employed for many engineering ceramics such as yttria-stabilised zirconia (YSZ).

At these higher temperatures the substrates deform by creep and the stresses can be deduced from specimen deformation assuming linear viscosity as originally proposed by Bordia and Scherer [11]. For example Chang and Jean [12] used this approach to analyse the stresses induced on co-firing a bi-layer of glass and a glass/ceramic composite between 500 and $900^{\circ} \mathrm{C}$ by measuring the curvature during co-firing of horizontal bi-layers. The uniaxial viscosities of the two layers were measured by thermo-mechanical analysis of bulk specimens of the individual materials. The resulting mismatch stresses were deduced to be less than 30 $\mathrm{kPa}$. However, no account was taken of the effects of gravity in this horizontal configuration which would have opposed the curvature caused by the mismatch stress.

As far as the authors are aware no studies have been reported of stresses induced by constrained sintering of typical engineering ceramics on dense substrates at high temperatures by measuring creep deformation of the bi-layer. The objective of the current work is to apply this method to study the sintering-induced stress for a typical fuel cell electrolyte film sintering on a dense substrate.

\section{Experimental Procedure}

The strategy adopted in the present study was to measure the stress in the sintering film by 
monitoring the resulting creep deformation of the constraining substrate. Therefore it was first necessary to establish the creep properties (viscosity) of the substrate material, without the sintering film. Lee et al. [13] described a method for measuring the viscosity of 8YSZ as a function of relative density by observing the deformation of thin horizontal simplysupported beams deforming under gravity. We have used a similar method employing in-situ observation of an end-clamped horizontal cantilever of the dense substrate material which creeps under gravity in this configuration and allows the viscosity of the substrate to be determined. For measurement of the stress induced by constrained sintering of the film, a bilayer beam (the dense substrate with the sintering film applied on one face) was clamped vertically to avoid the influence of gravity and the evolution of its curvature measured in-situ. The stress was then obtained from an analysis of the evolution of curvature of the bilayer and knowing the viscosity of the substrate obtained from the experiments with the horizontal substrate beams.

\section{Specimens}

The system chosen for study was a $3 \mathrm{YSZ}$ ( $3 \mathrm{~mol} \% \mathrm{Y}_{2} \mathrm{O}_{3}$ doped zirconia) film sintering on a dense 3YSZ substrate. This composition was used because although it does not have the highest ionic conductivity for an SOFC electrolyte in the YSZ system, it has the best mechanical properties and is used as an electrolyte by some SOFC developers. The film and substrate were chosen to be the same composition to ensure that no stresses would be generated by thermal expansion differences between the film and substrate. The substrates were commercially produced by Kerafol GmbH (Eschenbach, Germany) and were received in the form of $5 \times 5 \mathrm{~cm}$ square plates with nominal thicknesses of $300 \mu \mathrm{m}$ or $150 \mu \mathrm{m}$. The substrate microstructure is illustrated in Figure 1 and, from several such areas, the mean grain size was measured to be $0.46 \mu \mathrm{m}$.

The 3YSZ powder used to prepare the screen-printing ink and other specimens was supplied 
by MEL Chemicals, UK. Its particle size distribution was measured by light scattering and its parameters were: $d_{10}=0.38 \mu \mathrm{m} ; d_{50}=0.50 \mu \mathrm{m}$; and $d_{90}=0.77 \mu \mathrm{m}$. The specific surface area was $6.9 \mathrm{~m}^{2} \mathrm{~g}^{-1}$.

YSZ layers were deposited on the substrates (in the as-received condition) by screen printing (165 mesh screen and $2.5 \mathrm{~mm}$ gap) and the layers were oven dried at $120{ }^{\circ} \mathrm{C}$. At this stage the films were in the thickness range 10-13 $\mu \mathrm{m}$. Samples of both coated and uncoated substrates were then laser cut into $5 \mathrm{~mm}$ wide strips for stress measurements. The film thicknesses in the as-coated and dried condition and after the sintering experiment were measured using an interference microscope (ZYGO). Similar $5 \mathrm{~mm}$ wide strips without films deposited were laser cut for the viscosity measurements.

\section{Substrate viscosity}

The substrate viscosity was measured by observing a horizontal cantilever beam of an uncoated substrate strip bend under its own weight. The displacement of the tip of the beam relative to a rigid reference (Figure 2) was measured as a function of time during the heating cycle $(3 \mathrm{~K} / \mathrm{min})$ followed by an isothermal hold of between 1 and $3 \mathrm{~h}$ at the test temperature (in the range $1100-1350^{\circ} \mathrm{C}$ ). At least two experiments using nominally identical specimens were carried out at each isothermal temperature.

The specimens were placed in a furnace which had a window through which they were observed using a long-distance microscope (Infinity K2) and camera. The ceramic fixtures used to support the specimen were fabricated from 3YSZ blocks with all mating surfaces ground flat and accurately at right angles where critical. Digital images were recorded periodically and subsequently analysed to quantify dimensional changes. A typical image is shown in Figure 2. All images were analysed automatically using the MATLAB code (The MathWorks) to identify best-fit straight lines to the specimen and reference block outlines. These are shown on the image together with the dimension used to characterise the tip 
displacement, which is the difference in vertical coordinates between the point at the intersection of the two faces of the reference block and the point at the end of the beam on its neutral axis (midline). The two points are circled in Figure 2. This maximises the use of data points from the image and hence maximises the resolution of the displacement measurement which was determined to be $\pm 2 \mu \mathrm{m}$.

The results, in the region of constant temperature, were analysed using a theory developed for similar experiments on porous ceramics [13] and copper beams [14]. This assumes a linear uniaxial viscous creep law of the form $\sigma=E_{p} \dot{\varepsilon}$ and therefore analogous solutions to small displacement elastic problems can be used by replacing Young's modulus by the viscosity, $E_{p}$. This form of creep law should apply to polycrystalline beams having a constant grain size that is much smaller than the beam thickness, which was the case in this study.

The rate of vertical displacement of the horizontal beam, $y_{h}$, as a function of distance, $x$, from its clamped end (beam of length $L$ and thickness $h_{s}$ ) is given by [14]

$$
\frac{\partial y_{h}}{\partial t}=\frac{6 \rho g}{E_{p} h_{s}^{2}}\left[\frac{L^{2} x^{2}}{2}-\frac{L x^{3}}{3}+\frac{x^{4}}{12}\right]
$$

where $\rho$ is the density of the beam and $g$ is the acceleration due to gravity. Hence the rate of deflection at the free tip of the beam $(x=L)$ is

$$
\left(\frac{\partial y_{h}}{\partial t}\right)_{x=L}=\frac{3 \rho g L^{4}}{2 h_{s}^{2} E_{p}}
$$

The data for tip displacement as a function of time in the constant temperature region thus allow the creep viscosity $E_{p}$ to be determined.

\section{Sintering-induced stress}

The deformation caused by the sintering-induced stress was measured in a similar way, but with a sintering film applied to the substrate and in vertical orientation so that there was little deformation due to gravity (Figure 3). The possible influence of gravity as the bilayer beam 
bends away from the vertical is discussed in the Appendix. The distance between the tip of the specimen and the reference block was measured as a function of time as the sinteringinduced stress caused the specimen to bend away from the reference using the same heating cycle (after binder burn out at $500^{\circ} \mathrm{C}$ ) as in the horizontal experiment and for holding temperatures from 1100 to $1350^{\circ} \mathrm{C}$. A similar approach to that described for analysis of images from the horizontal beam experiment was adopted for the vertical bilayer experiments. After fitting straight lines to the beam and reference outlines, the tip deflection was determined by measuring the distance between the two circled points shown on the image in Figure 3. At least two experiments using nominally identical specimens were carried out at each isothermal temperature.

Hence the beam curvature, $\kappa$, was obtained from

$$
\kappa=\frac{2 y_{v, L}}{L^{2}}
$$

where $y_{v, L}$ denotes the tip displacement in the vertical configuration. The sintering-induced stress was then calculated from the curvature using the viscous analogue of Stoney's formula for beam bending (when the film is much thinner than the substrate)

$$
\sigma=\frac{h_{s}^{2} E_{p}}{6 h_{f}}\left(\frac{d \kappa}{d t}\right)
$$

where $h_{f}$ is the thickness of the film. In this expression the bending rate is determined by the product of the stress and the film thickness, which changes as the film shrinks. The film thickness at the start of and end of the isothermal period was estimated from a separate study of the constrained sintering kinetics of the films [15] and the measured values of the initial and final film thicknesses. 


\section{Results and discussion}

\section{Substrate viscosity}

Figure 4 shows examples of the dense substrate deformation (beam tip displacement) under gravity in the horizontal configuration during the isothermal hold period at $1250^{\circ} \mathrm{C}$ and illustrates two general points that were common in all the experiments. The first is a gradual slowing of the deformation rate and the second is that there is considerable difference between nominally identical specimens

The slowing of the deformation rate implies an increase in viscosity with either time or strain, whereas the theory leading to Equations 1 and 2 assumes a viscosity that is independent of time and strain. Chokshi [16] has summarised creep behaviour in YSZ polycrystalline ceramics. Most experimental data were obtained at higher temperatures than the current experiments, but in many cases it has been reported that in the relationship $\dot{\varepsilon} \propto \sigma^{n}, n$ is often $>1$; being typically approximately 2 for low stress and approaching 1 only for coarse-grained $(\sim 1 \mu \mathrm{m})$ material at high stress $(30-200 \mathrm{MPa})$. In order to test the validity of the linear viscous assumption in the present study, we have compared the final profile of the beam at room temperature after the creep experiment with that predicted for different values of stress exponent $n$. The details of the analysis are given in the Appendix and the expression for the beam profile (Equation A10) agrees with Equation 1 for $n=1$. A typical example of the measured profile compared with the theoretical profile is shown in Figure 5. In the fitting procedure the location of $x=0$ was allowed to vary since the exact location of the end of the clamped part of the beam could not be reliably identified by inspection after dismantling the experiment. The goodness of fit (from the sum of residual squares) to the measured profile for $n=1$ is 0.9996 , whereas for $n=2$ it is only 0.995 . The better fit for $n=1$ is also evident by inspection of Figure 5. The goodness of fit was also calculated as a function of $n$ and 
found to be $\geq 0.9995$ for $n$ in the range 0.6 to 1.1 . It can therefore be concluded that linear creep $(n=1)$ gives a satisfactory description of the creep behaviour and there is no evidence for a higher stress exponent in the substrate material. This appears to contradict the behaviour reported in previous studies of creep in 3YSZ. However, the previous studies concentrated on superplastic deformation with finer grained material at higher temperatures than in the present experiments. The superplastic experiments involve considerable grain growth during the creep deformation and Chokshi [16] has shown that when grain growth is taken into account the superplastic creep is consistent with the Coble creep mechanism (grain boundary diffusion) for which $n=1$. In the present study all the experiments were conducted at temperatures less than the substrate sintering temperature and there was negligible grain growth during the creep experiments. Therefore there is no incompatibility between the present results and those reported earlier.

However, the slowing of the creep rate (increasing viscosity) during the isothermal hold cannot be explained by grain growth because it was evident even at the lowest temperatures. In Coble creep the viscosity is proportional to the cube of the grain size, but even with such a sensitive dependence this cannot account for the observed increase in viscosity since any change in grain size is too small to be detected. The cause of the observed increase in viscosity is thus unclear, but could be related to a change in grain boundary diffusivity resulting from the creep deformation (strain hardening). Consequently, the viscosity was calculated as the average over the isothermal hold period and the results are plotted in Arrhenius form in Figure 6. The experiments showed some variation in creep viscosity from specimen to specimen and the error bars in Figure 6 represent the percentage standard deviation averaged over the whole set of specimens. The Arrhenius plot shows a distinct curvature with lower activation energy at lower temperature (approximately $250 \mathrm{~kJ} \mathrm{~mol}^{-1}$ ) and higher activation energy at higher temperatures (approximately $500 \mathrm{~kJ} \mathrm{~mol}^{-1}$ ). This 
might be due to a change in creep mechanism from Coble creep (grain boundary diffusion) at lower temperatures to Nabarro-Herring creep (lattice diffusion) at higher temperatures. The strains in the present experiments are of the order of $10^{-4}$ and the strain rates of the order of $10^{-8} \mathrm{~s}^{-1}$. These are both much lower than are typical for creep studies of this material which concentrate on its superplastic behaviour and large strains. Chokshi [16] analysed experimental creep data for $1000^{\circ} \mathrm{C}$ and $1400^{\circ} \mathrm{C}$ and concluded that stress exponents greater than unity can be explained by grain growth occurring during the creep experiments. The results of that analysis have been used to estimate the viscosity for tetragonal YSZ with a grain size equal to that of the substrates used in the present study. The resulting viscosities are shown in Figure 6 compared with the present results. Also shown are viscosities estimated from creep experiments assuming linear viscous creep at $1450^{\circ} \mathrm{C}$ [17] and $1350^{\circ} \mathrm{C}$ [18]. Despite the uncertainties, the present results are reasonably consistent with the existing literature in their approximate order of magnitude and general trend. However, there are still some significant differences. For example, Zapata-Solvas et al. [18] claim a temperaturedependent threshold stress below which there is no creep deformation, whereas in the present study we observe creep at very low stresses. This difference could be due to differences in grain boundary chemistry in the specimens used in the different studies. Therefore there are still significant unresolved fundamental issues concerning creep of YSZ.

\section{Sintering-induced stress}

Figure 7 shows an example of tip displacement as a function of time at the isothermal hold temperature for a vertical experiment with a coated substrate beam. The bending profile was measured after each experiment and compared with the theoretical profile which is an arc of a circle. An example is shown in Figure 8 from which it can be seen that the profile is an excellent fit to the arc of a circle as expected theoretically. (It should be noted that the maximum strain in the film caused by the bending is $\kappa h_{s} / 2$ and in the experiments is typically 
$10^{-4}$. Since this is much smaller than the unconstrained sintering strain, the bending has no effect on the sintering-induced stress in the constrained film.)

Therefore the specimen curvature can be calculated from the tip deflection in the vertical experiment, $y_{v, L}$, using

$$
\kappa=\frac{2 y_{v, L}}{L^{2}}
$$

It can be seen from Figure 7 that the vertical experiments exhibit two features in common with the horizontal ones. The first is a variability in the results of nominally identical experiments, which originates mainly from the variability in creep properties of the substrates. The second is that the rate of tip displacement slows down with time. This might be because the substrate viscosity is increasing with time (or strain) or because the sinteringinduced stress is decreasing with time. Since the reason for the increasing substrate viscosity is not currently understood, it is not possible to deduce how the sintering-induced stress is changing with time. Therefore we have analysed the results by taking the average deformation rate over the isothermal hold period. Similarly, we have used the average film thickness during the isothermal period when calculating the film stress from Equation 4. The film density estimated from densification experiments [15] at the start and end of the isothermal period of the corresponding vertical beam experiments is shown in Figure 9 and the corresponding sintering-induced stresses averaged over the same isothermal period in Figure 10. The error bars are the percentage standard deviation averaged over the whole set of experiments and reflect the specimen-to-specimen variability in the results. The sinteringinduced stress is of the order 1-3 MPa and peaks in the middle of the temperature range studied. However, this is not necessarily an effect only of temperature since the average degree of densification during the isothermal period also increases with the holding temperature (Figure 9).

Using the linear viscous deformation model, the sintering-induced stress for a constrained 
film is given by [Error! Bookmark not defined.]

$$
\sigma=\frac{E_{p, f} \dot{\varepsilon}_{f}}{1-v_{p, f}}
$$

where $\dot{\varepsilon}_{f}$ is the unconstrained sintering rate and $E_{p, f}$ and $v_{p, f}$ are the viscosity and Poisson ratio of the film. Both $E_{p, f}$ and $\dot{\varepsilon}_{f}$ are controlled by similar diffusion process (but in opposite senses); namely by the slowest diffusing cation. Therefore the product is not particularly sensitive to either temperature or time, but will change as the microstructure develops and/or changes in temperature change the relative importance of different diffusion pathways. The relative activation energies for the available diffusion pathways are expected to be in the order surface diffusion $<$ grain boundary diffusion $<$ lattice diffusion. At low temperatures surface diffusion is favoured which can contribute to creep deformation (e.g. by transporting material around the necks that form between particles in the early stages of sintering). Densification, on the other hand requires grain boundary diffusion which is relatively more difficult at lower temperatures. Thus the product $E_{p, f} \dot{\varepsilon}_{f}$ tends to be low at low temperature and low relative density. Conversely at higher temperatures grain boundary diffusion becomes faster relative to surface diffusion and, as the relative density increases, surface diffusion becomes ineffective for creep deformation. Thus the product $E_{p, f} \dot{\varepsilon}_{f}$ increases at first with increasing temperature. However, as the temperature is increased further the unconstrained densification rate slows down relative to the creep rate because the distance between pores, which characterises the scale of diffusion required for densification, becomes greater than the grain size, which is the characteristic scale of diffusion for creep deformation. Hence the product $E_{p, f} \dot{\varepsilon}_{f}$ becomes smaller and, as the film approaches full density, the stress tends towards zero even though the viscosity is high. The maximum stress therefore occurs around the mid-range of densification and temperature as seen in Figures 9 and 10. Typical microstructures of the sintered films are shown in Figure 11. The 
micrographs show that there is very little grain growth during densification. The pores visible from the top of the film tend to be elongated and have a size of the order of $1 \mu \mathrm{m}$.

The stresses measured in this study are significantly larger than those measured in sintering of other constrained films mentioned in the introduction. However, those systems were not crystalline ceramics sintering by solid state diffusion. Zuo et al. [19] have measured the uniaxial sintering stress using a hot forging technique for isostatically pressed bulk alumina specimens made from a powder with $150 \mathrm{~nm}$ grain size. They found the stress was of the order of a few $\mathrm{MPa}$ and peaked at approximately $3.5 \mathrm{MPa}$ at a relative density of approximately $80 \%$. Similarly, Ikegami et al. [20] measured the uniaxial sintering stress in alumina rods using a tensile loading method and found a maximum of approximately 3.6 $\mathrm{MPa}$ at $1200^{\circ} \mathrm{C}$. Thus the present results are in qualitative agreement with the studies of bulk alumina reported in the literature.

The constrained sintering-induced stress is also closely related to the thermodynamic sintering potential which is a function of the surface energy and the pore structure $[21,22]$. From the principle of virtual work the sintering potential (equivalent hydrostatic stress on the porous unconstrained body) is given by

$$
\Sigma=\gamma_{s v} \frac{d S}{d V}
$$

where $\gamma_{s v}$ is the surface energy, $S$ is the internal surface area and $V$ is the external (bulk) volume and any contribution from the grain boundaries is neglected. The relationship between $S$ and $V$ is dependent on the details of the pore structure and how it evolves, but for a uniform population of spherical pores of radius $r$, Equation 6 gives $\Sigma=2 \gamma_{s v} / r$. Unfortunately, as far as the authors are aware there are no reliable experimental data for the surface energy of zirconia. Redfern et al. [23] calculated the surface energies of various t$\mathrm{ZrO}_{2}$ surfaces using atomistic simulation corresponding to $0 \mathrm{~K}$ and found typical values of $2 \mathrm{~J}$ $\mathrm{m}^{-2}$. (The surface energy at higher temperature is likely to be lower due to the greater entropy 
of surface atoms than bulk atoms.) Assuming this value for the surface energy and a pore size of the order of $1 \mu \mathrm{m}(r=0.5 \mu \mathrm{m})$, then the sintering potential is estimated to be approximately $8 \mathrm{MPa}$. This is reasonably consistent with the constrained sintering-induced stress measured here considering the approximations involved in calculating the sintering potential.

\section{Conclusions}

The creep rate of thin beams of 3YSZ is linearly dependent on stress at the low stresses and strains involved in the present work. The creep viscosity appeared to increase with strain (time) which might be due to changes in grain boundary composition. The viscosity has a higher activation energy at temperatures above approximately $1250^{\circ} \mathrm{C}$ which could be due to a change from Coble to Nabarro-Herring creep. The magnitudes of the creep viscosities are in reasonable agreement with other data in the literature.

The in-plane stress induced during constrained sintering of a 3 YSZ film has a maximum value of approximately $3 \mathrm{MPa}$ at $1200^{\circ} \mathrm{C}$. This behaviour is consistent with literature results reported for constrained sintering of bulk alumina. The stress induced by the constraint is of a similar order to the estimated sintering potential. 


\section{References}

1 R.W. Steinbrech, A. Caron, G. Blass, and F. Dias, "Influence of sintering characteristics on component curvature of electrolyte-coated anode substrates" in Proceedings of SOFC V, Electrochemical Society (1997) 727-736.

2 P. Costamagna, A. Selimovic, M. Del Borghi and G. Agnew, "Electrochemical model of the integrated planar solid oxide fuel cell (IP-SOFC)", Chemical Engineering Journal, 102 [1] 61-69 (2004)

3 T. J. Garino and H. K. Bowen, "Kinetics of constrained-film sintering", J. Am. Ceram. Soc., 73 [2] 251-257 (1990)

$4 \quad$ Y. Zhao and L.R. Dharani, "Theoretical-model for the analysis of a ceramic thin-film sintering on a non-sintering substrate", Thin Solid Films, 245 [1-2] 109-114 (1994)

5 A. Jagota and C.Y. Hui, "Mechanics of sintering thin-films .2. Cracking due to selfstress", Mech. Mater., 11 [3] 221-234 (1991).

6 R.K. Bordia and A. Jagota, "Crack-growth and damage in constrained sintering films", J. Am. Ceram. Soc., 76 [10] 2475-2485 (1993)

7 J. Bang and G.Q. Lu, "Constrained-film sintering of a borosilicate class - in-situ measurement of film stresses", J. Am. Ceram. Soc., 78 [3] 813-815 (1995)

8 J.N. Calata, A. Matthys and G.Q. Lu, "Constrained-film sintering of cordierite glassceramic on silicon substrate", J. Mater. Res., 13 [8] 2334-2341 (1998)

9 J. W. Choe, J. N. Calata and G. Q. Lu, "Constrained-film sintering of a gold circuit paste", J. Mater. Res., 10 [4] 986-994 (1995)

10 Y.-C. Lin and J.-H. Jean, "Constrained sintering of silver circuit paste", J. Am. Ceram. Soc., 87 [2] 187-191 (2004) 
11 R.K. Bordia and G.W. Scherer, "Constrained sintering: I, constitutive model for a sintering body", Acta metallurgica, 36 [9] 2393 (1988)

12 J. C. Chang and J. H. Jean, "Self-constrained sintering of mixed low-temperaturecofired ceramic laminates", J. Am. Ceram. Soc., 89 [3] 829-835 (2006)

13 G.L.Messing S.-H. Lee and D.J. Green, "Bending creep test to measure the viscosity of porous materials during sintering”, J. Am. Ceram. Soc., 86[6] 877-882 (2003).

14 V. Srivastava, H. Jones and G.W. Greenwood, "The-creep of thin beams under small bending moments", Proceedings of the Royal Society A-Mathematical Physical and Engineering Sciences, 462 [2073] 2863-2875 (2006).

15 to be published

16 A.H. Chokshi, "Diffusion, diffusion creep and grain growth characteristics of nanocrystalline and fine-grained monoclinic, tetragonal and cubic zirconia", Scripta Mat., 48(6) 791-796 (2003).

17 A.H. Chokshi, "The role of diffusion creep in the superplastic deformation of 3 mol\% yttria stabilized tetragonal zirconia”, Scripta Mat., 42 (3) 241-248 (2000).

18 E. Zapata-Solvas, D. Gómez-García, C. García-Gañán and A. Domínguez-Rodríguez, "High temperature creep behaviour of 4 mol\% yttria tetragonal zirconia polycrystals (4-YTZP) with grain sizes between 0.38 and $1.15 \mu \mathrm{m}$ ", J. European Ceram. Soc., 27 [11] 3325-3329 (2007).

19 R. Zuo, E. Aulbach and J. Rödel, "Experimental determination of sintering stresses and sintering viscosities", Acta Mater., 51 [15] 4563-4574 (2003).

20 T. Ikegami, N. Iyi and I. Sakaguchi, "Evaluation of sintering stresses of an Al2O3 powder with a self-loading apparatus", Ceramics International, 35 [8] 3185-3194 (2009)

21 J. Svoboda, H. Riedel, and H. Zipse, "Equilibrium pore surfaces, sintering stresses and constitutive equations for the intermediate and late stages of sintering--I. 
computation of equilibrium surfaces", Acta Metallurgica et Materialia, 42(2) 435-443 (1994).

22 H. Riedel, H. Zipse, and J. Svoboda, Equilibrium pore surfaces, sintering stresses and constitutive equations for the intermediate and late stages of sintering--II. Diffusional densification and creep. Acta Metallurgica et Materialia, 1994. 42(2): p. 445-452.

23 S. E. Redfern, R. W. Grimes and R. D. Rawlings, "The hydroxylation of t-ZrO2 surfaces", Journal of materials chemistry, 11 [2] 449-455 (2001) 


\section{Appendix}

\section{Analysis of beam profile}

Let the creep behaviour be described by the relationship

$$
\sigma=A^{-1} \dot{\varepsilon}^{1 / n}
$$

For the beam bent as a result of creep (Figure A1), the strain can be expressed as $\varepsilon=z / R(x)$, where $R(x)$ is the local radius of curvature at horizontal coordinate $x$ and $z=0$ is the neutral axis.

The moment on the rectangular cross section of the cantilever beam is

$$
M=\int_{-h / 2}^{h / 2} \sigma w z d z
$$

where $w$ is the width and $h$ is the thickness of the beam.

Hence

$$
M=\frac{w h^{(2+1 / n)}}{2^{(1+1 / n)}(2+1 / n) A \dot{R}(x)^{1 / n}}
$$

or

$$
\frac{1}{\dot{R}}=\frac{M^{n} A^{n}}{I^{n}}
$$

where

$$
I=\frac{w h^{(2+1 / n)}}{2^{(1+1 / n)}(2+1 / n)}
$$

For the cantilever beam the moment arising from the body weight is a function of $x$

$$
M(x)=\frac{(2-x)^{2}}{2} w h g \rho
$$

with $g$ the gravitational acceleration and $\rho$ the density of the beam material.

When the deflection $y(x)$ is small, the local curvature of the beam can be approximated by: 


$$
\frac{1}{R(x)}=\frac{d^{2} y}{d x^{2}}
$$

Therefore the beam profile can be expressed:

$$
y(x)=\int_{0}^{t} \int_{0}^{L} \int_{0}^{L} \frac{1}{\bullet} d x d x d t
$$

with the boundary conditions $z=0$ at $x=0 ; \frac{d z}{d x}=0$ at $x=0$.

If the creep rate is assumed to be independent of the time the solution is

$$
y(x)=\frac{t A^{n} 2(2+1 / n)^{n} g^{n} \rho^{n}}{h^{n+1}}\left[\frac{(L-x)^{2 n+2}}{(2 n+1)(2 n+2)}+\frac{L^{2 n+1} x}{2 n+1}-\frac{L^{2 n+2}}{(2 n+1)(2 n+2)}\right]
$$

\section{Influence of gravity on vertical experiment}

Considering a cross section of the beam at height $x$ from the clamping point, it must support the body weight of a section of beam $(L-x)$. The body weight provides a bending moment:

$$
M_{G}=\frac{\rho g b h_{s}(L-x)^{2} \sin \theta}{2}
$$

where $\theta$ is the angle between the vertical and the local tangent to the beam. $\sin \theta$ is related to the curvature, ie., $\sin \theta=(3 L+x) / 4 R$, so the above equation can be rewritten as:

$$
M_{G}=\frac{\rho g b h_{s}(L-x)^{2}(3 L+x) \kappa}{8}
$$

where $\kappa$ is the curvature.

Therefore for the vertical experiments, the total bending moment is provided not only by the sintering-induced stress, but also by gravity to give the local rate of change of curvature: 


$$
\dot{\kappa}(x, t)=\frac{3 \rho g(L-x)^{2}(3 L+x) \kappa}{2 h_{s}^{2} E_{P}}+\frac{6 h_{f} \sigma_{s}}{h_{s}^{2} E_{P}}
$$

Therefore numerical simulation based on the above equation was carried out to assess the influence of the gravity. Using parameters taken from the experimental study, the gravitational contribution to the deflection of the end of the beam, for a sintering-induced stress of $2 \mathrm{MPa}$, is shown in Figure A2. The contribution increases with time as the beam bends further away from the vertical. However, over a period of $2 \mathrm{~h}$ the contribution is only $3 \%$ and is negligible on this time-scale.

An error due to gravity also arises if the beam is initially not perfectly vertical. If the misorientation angle is $\delta$ then Equation $\mathrm{A} 12$ is modified to give:

$$
\dot{\kappa}(x, t)=\frac{3 \rho g(L-x)^{2}[(3 L+x) \kappa+4 \delta]}{2 h_{s}^{2} E_{P}}+\frac{6 h_{f} \sigma_{s}}{h_{s}^{2} E_{P}}
$$

The effect of a misalignment of $1^{\circ}$ is shown in Figure A3 for the same parameters as figure A3. The simulation shows that the tip deflection is not sensitive to misorientation of this order. 


\section{Figure captions}

Figure 1 Substrate microstructure (secondary electron image of surface).

Figure 2 a) Schematic of the arrangement for measuring the substrate viscosity (the box indicates the region observed by the long distance microscope and the arrow the measured beam tip displacement), and b) an example of an image. The broken lines show the fitted outlines of the beam and the reference block and the centre line of the beam. The circles show the points used for measuring the beam displacement.

Figure 3 a) Schematic of the arrangement for measuring sintering-induced stress (the box indicates the region observed by the long distance microscope and the arrow the measured beam tip displacement), and b) an example of an image. The broken lines show the fitted outlines of the beam and the reference block and the centre line of the beam. The circles show the points used for measuring the beam displacement.

Figure 4 Example of tip deflection as a function of time for two horizontal beam specimens (150 $\mu \mathrm{m}$ thickness and $40 \mathrm{~mm}$ length) during the isothermal hold period at $1250^{\circ} \mathrm{C}$.

Figure 5 Profile of $300 \mu \mathrm{m}$ thick beam after horizontal creep for $1.5 \mathrm{~h}$ at $1350{ }^{\circ} \mathrm{C}$; a) fitted to theory for a stress exponent $n=1$; and $\mathrm{b}$ ) fitted to theory for a stress exponent $n=2$. Figure 6 Arrhenius plot of the viscosity of the 3YSZ substrates

Figure 7 Example of tip deflection as a function of time for two vertical coated beam specimens (150 $\mu \mathrm{m}$ thickness and $40 \mathrm{~mm}$ length) during the isothermal hold period at $1250^{\circ} \mathrm{C}$.

Figure 8 Profile of $300 \mu \mathrm{m}$ thick beam coated with sintering film after the vertical experiment at $1350^{\circ} \mathrm{C}$ fitted to the arc of a circle.

Figure 9 The estimated relative density of the sintering film at the start and at the end of 
the isothermal hold at each temperature studied.

Figure 10 Sintering-induced stress in 3YSZ films averaged over the isothermal hold period at each temperature.

Figure 11 Secondary electron micrographs of the top surfaces of constrained 3YSZ films after sintering for $1 \mathrm{~h}$ at a) $1200^{\circ} \mathrm{C}$; and b) $1300^{\circ} \mathrm{C}$. 


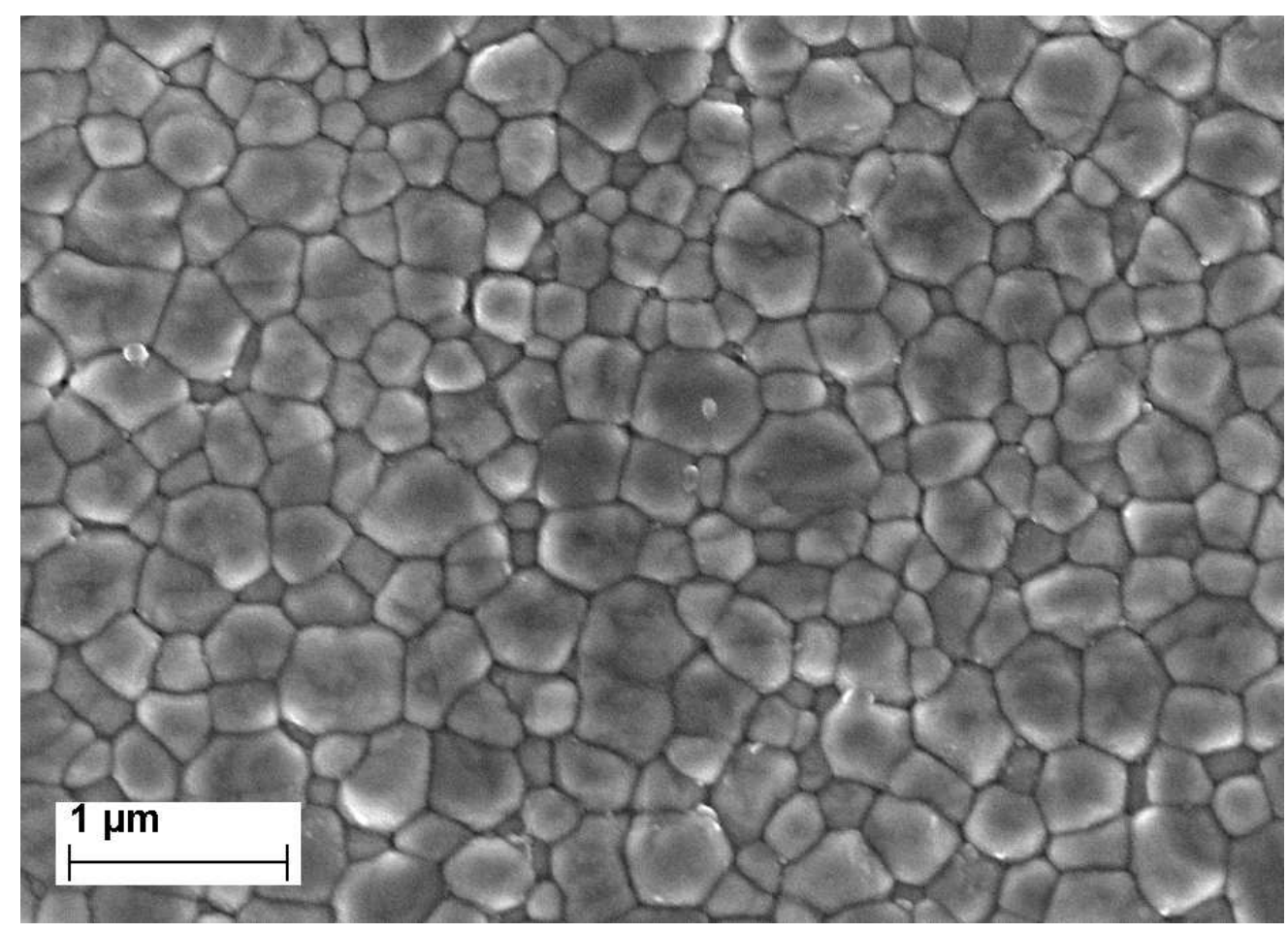

Figure 1 Substrate microstructure (secondary electron image of surface). $327 \times 235 \mathrm{~mm}(72 \times 72$ DPI $)$ 
b)

a)

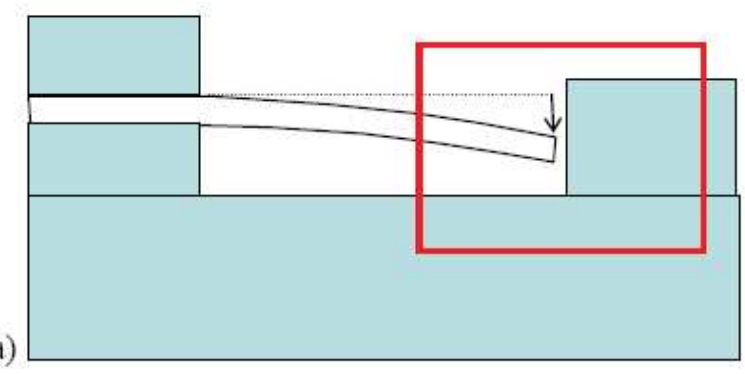

Figure 2

$241 \times 222 \mathrm{~mm}(72 \times 72$ DPI $)$ 
b)

a)
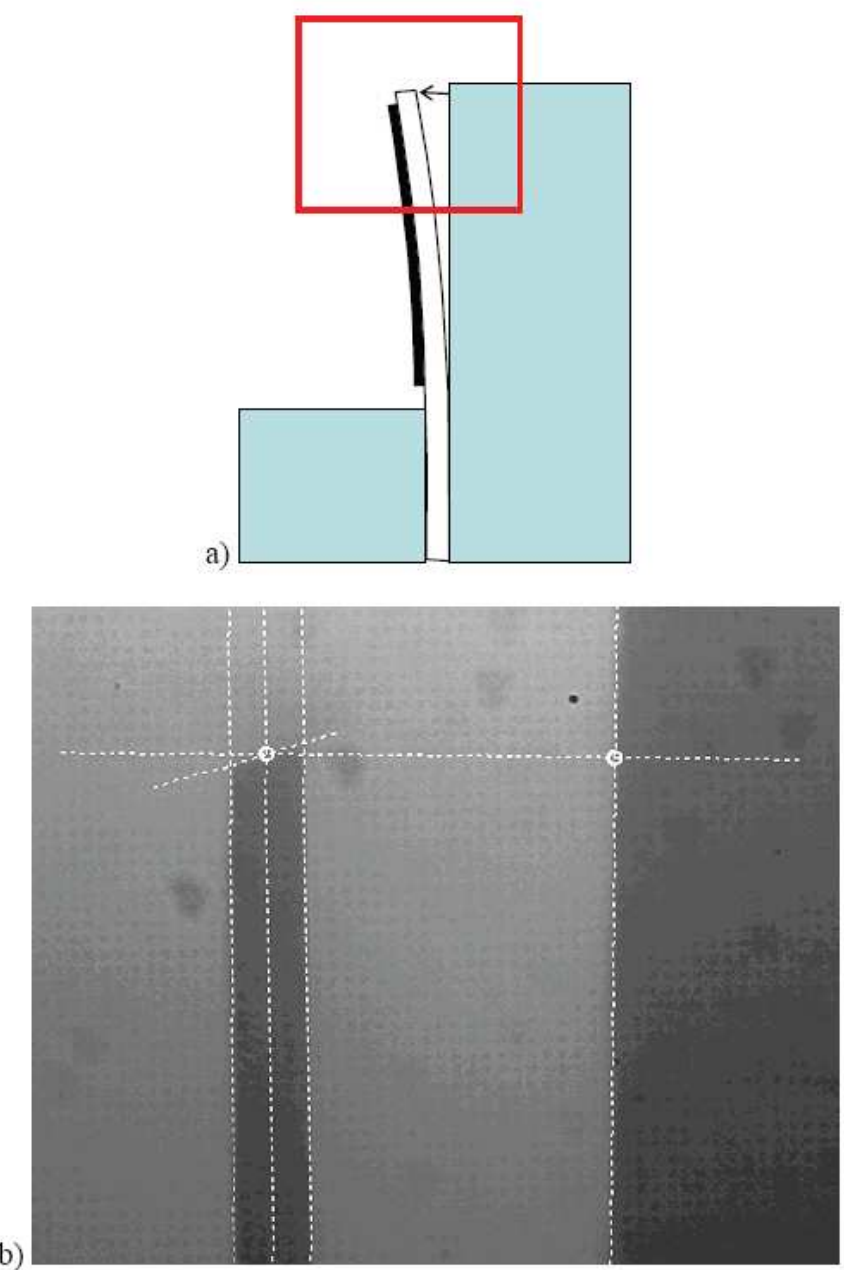

Figure 3 $227 \times 319 \mathrm{~mm}(72 \times 72 \mathrm{DPI})$ 


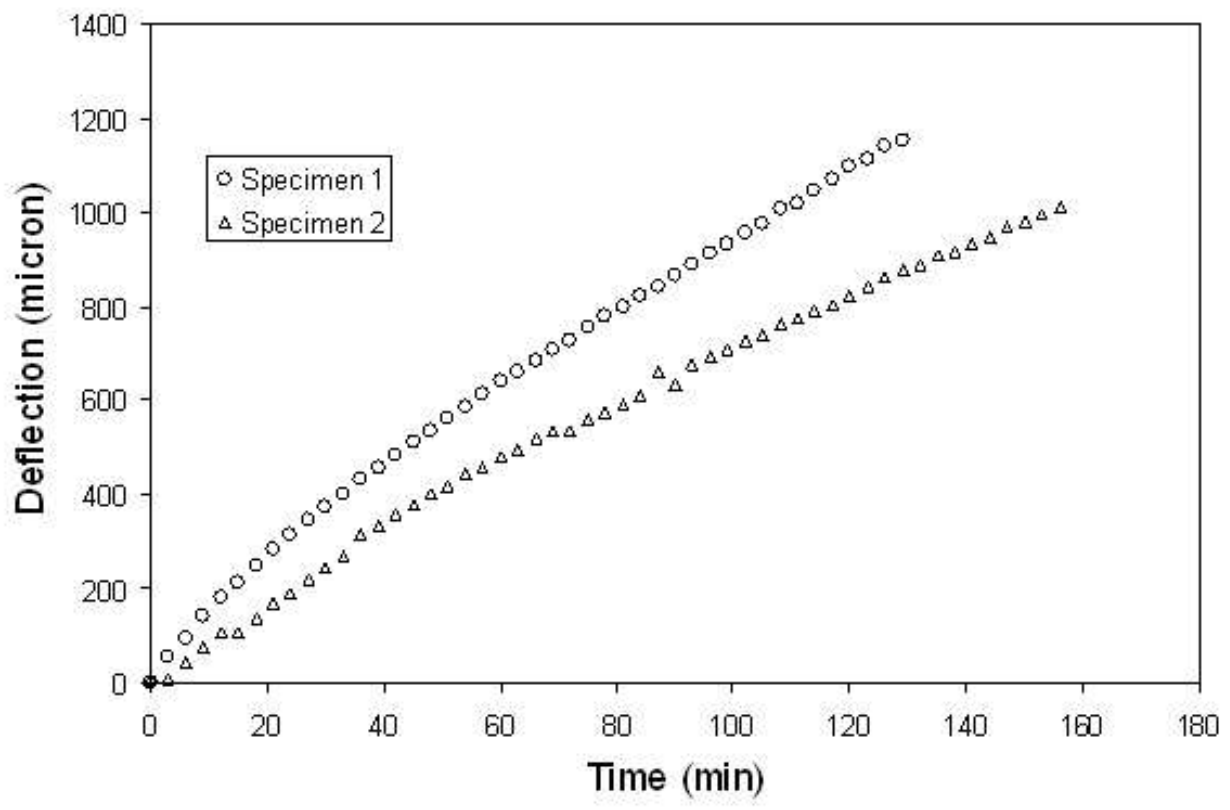

Figure 4 $212 \times 138 \mathrm{~mm}(72 \times 72 \mathrm{DPI})$ 


1
2
3
4
5
6
7
8
9
10
11
12
13
14
15
16
17
18
19
20
21
22
23
24
25
26
27
28
29
30
31
32
33
34
35
36
37
38
39
40
41
42
43
44
45
46
47
48
49
50
51
52
53
54
55
56
57
59
60

a)
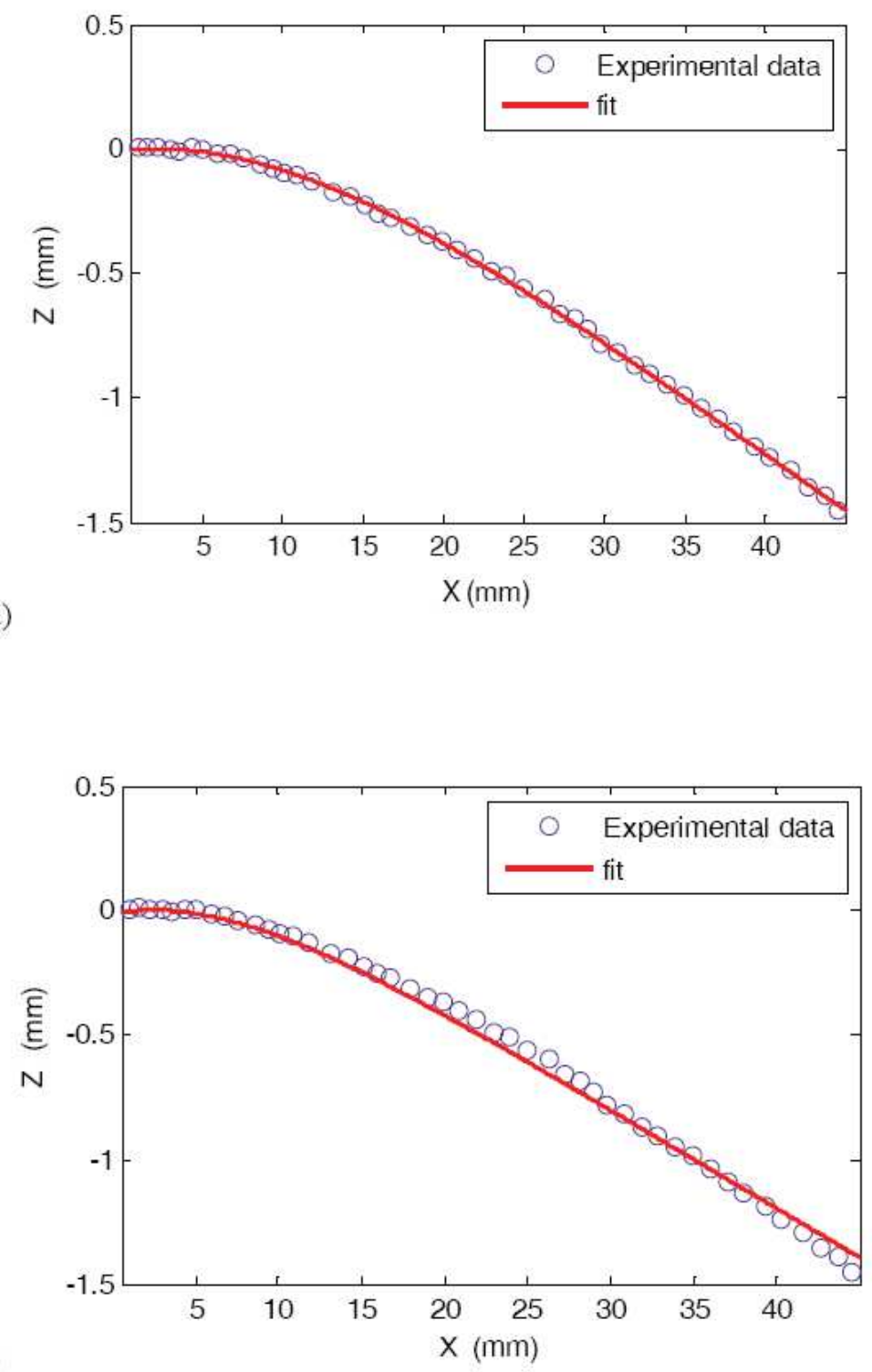

b)

Figure 5

$217 \times 306 \mathrm{~mm}(72 \times 72 \mathrm{DPI})$

Journal of the American Ceramic Society 


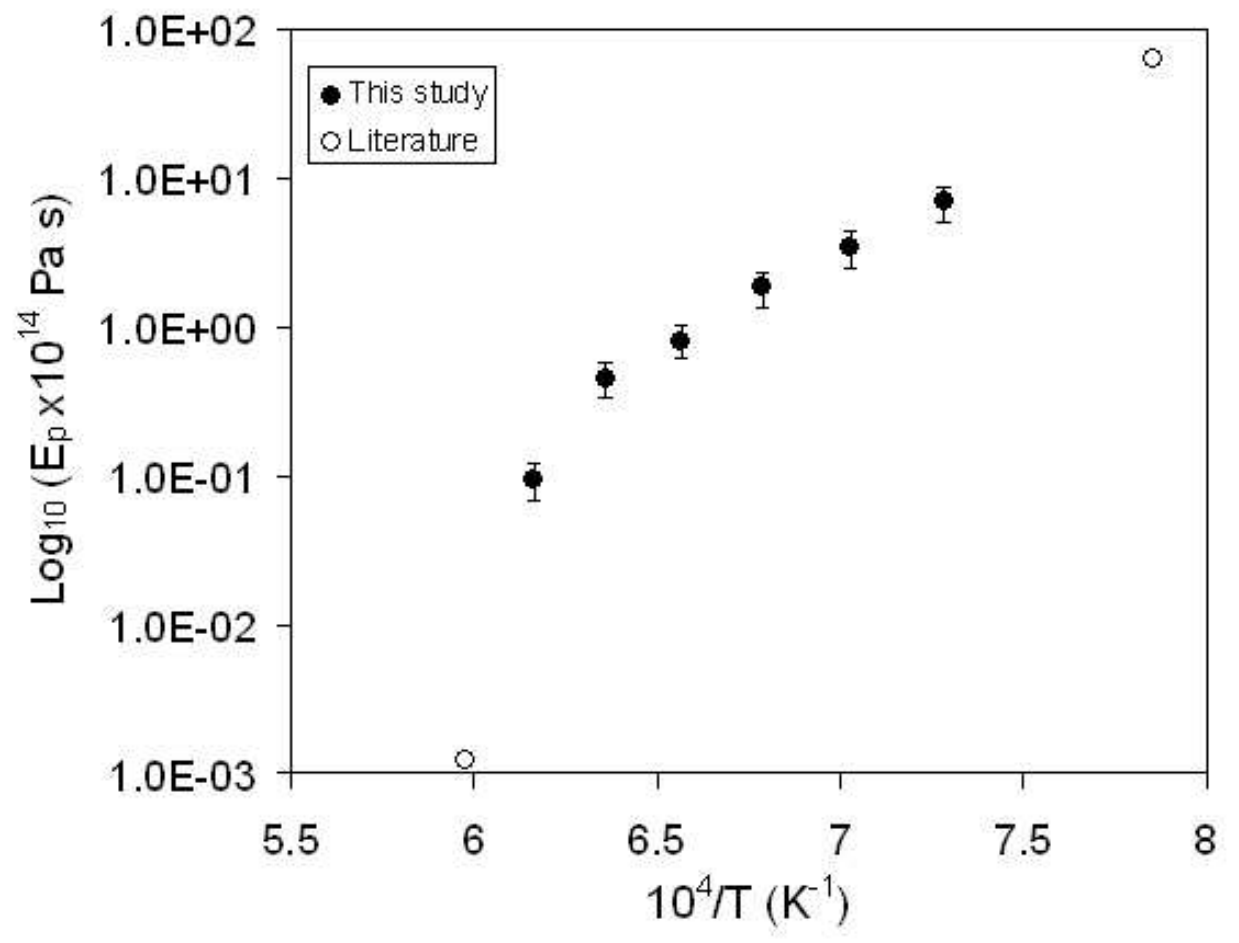

Figure 6 $209 \times 171 \mathrm{~mm}(72 \times 72$ DPI $)$

Journal of the American Ceramic Society 


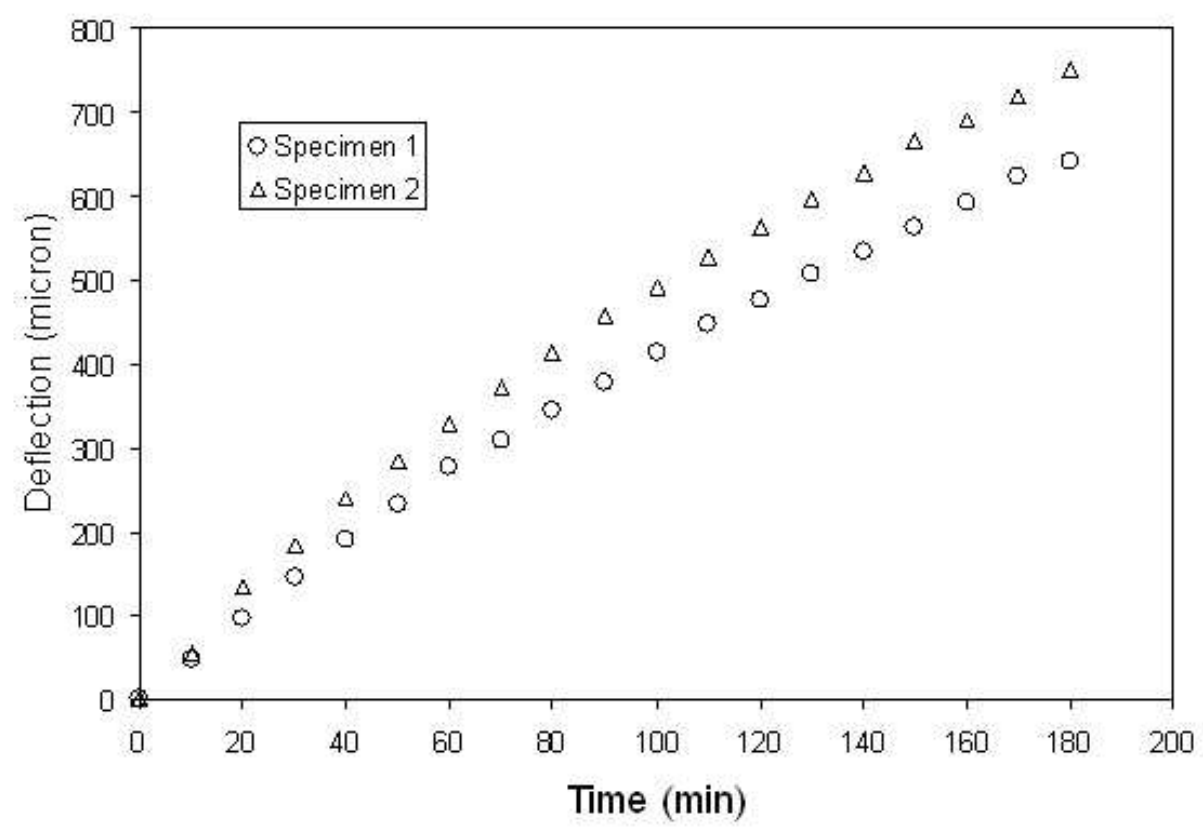

Figure 7

$212 \times 142 \mathrm{~mm}(72 \times 72$ DPI $)$

35

36

37

38

39

40

41

42

43

44

45

46

47

48

49

50

51

52

53

54

55

56

57

58

59

60

Journal of the American Ceramic Society 
1

2

3

4

5

6

7

8

1

10

11

12

14

15

16

17

18

19

20

21

22

23

24

25

26

27

28

29

30

31

32

33

34

35

36

37

38

39

40

41

42

43

44

45

46

47

48

49

50

51

52

53

54

55

56

57

58

59

60

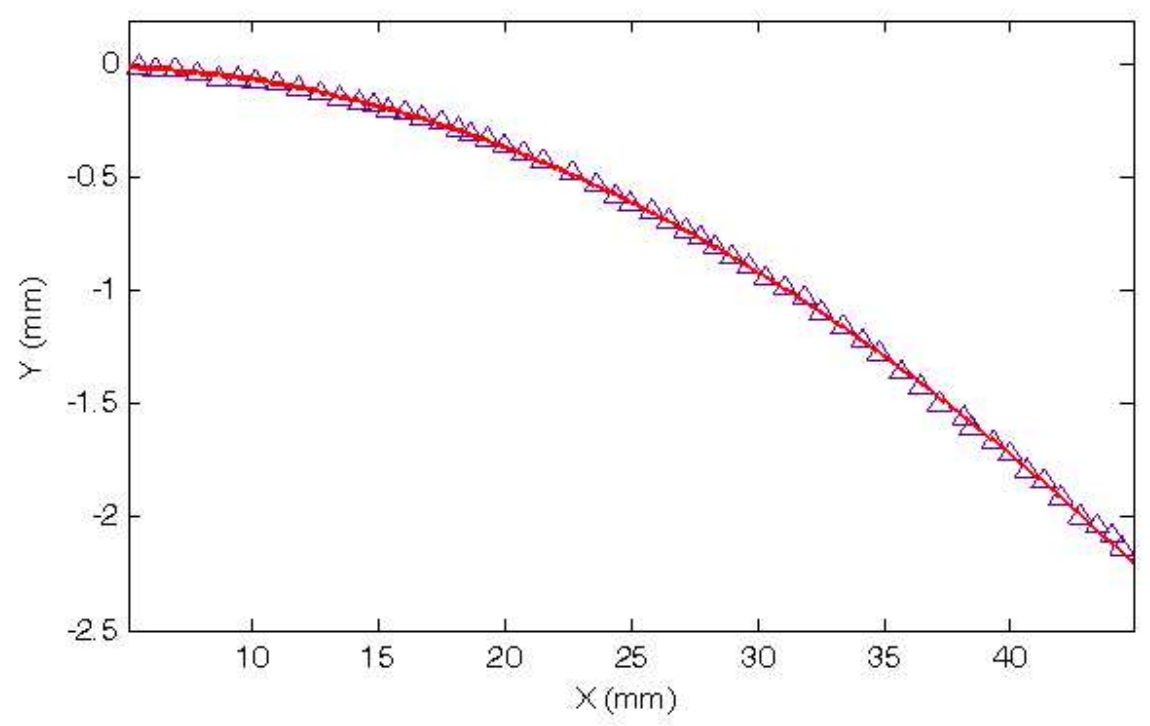

Figure 8

$235 \times 138 \mathrm{~mm}(72 \times 72$ DPI $)$ 


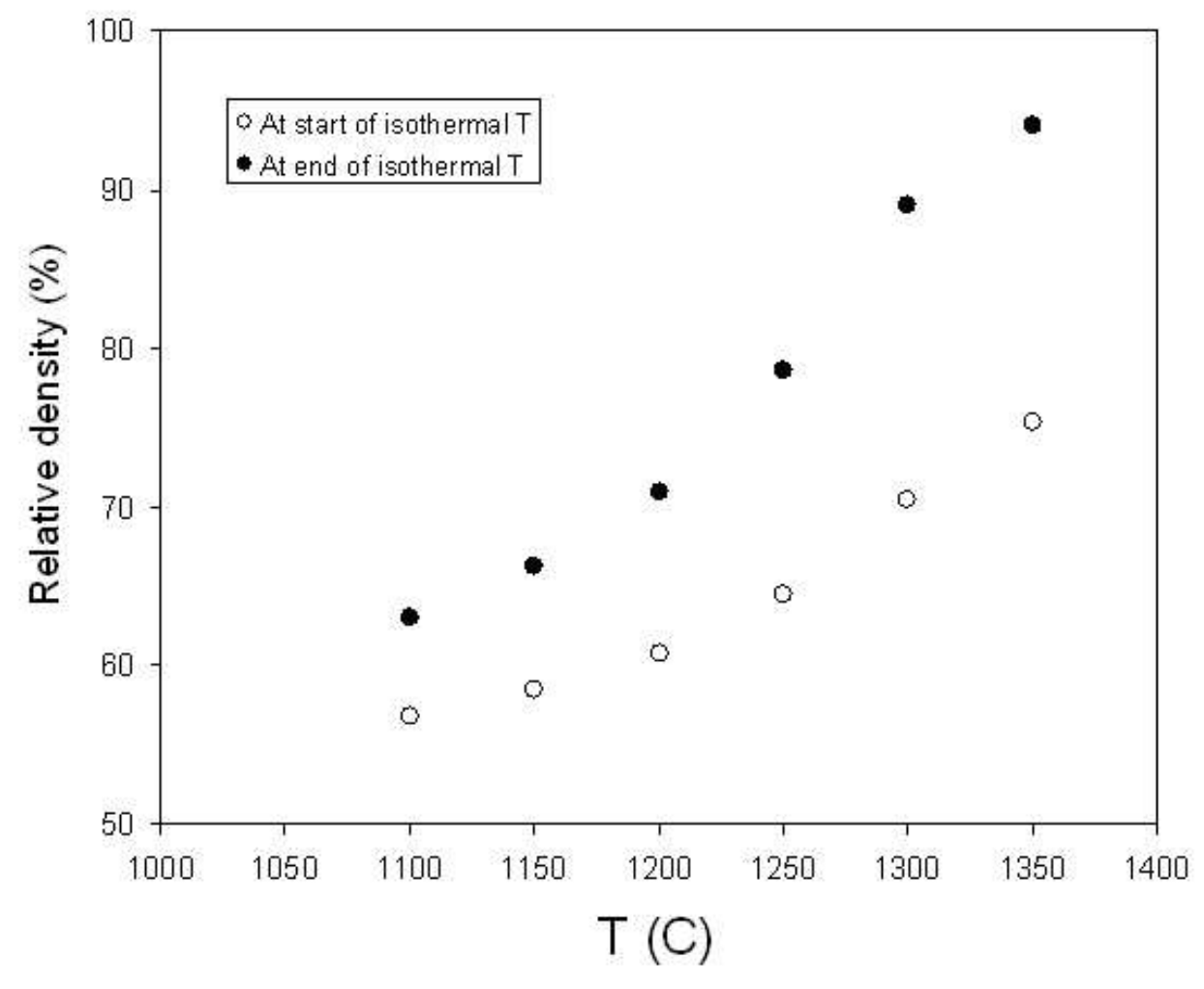

Figure 9

$212 \times 172 \mathrm{~mm}(72 \times 72$ DPI $)$

Journal of the American Ceramic Society 


1
2
3
4
5
6
7
8
9
10
11
12
13
14
15
16
17
18
19
20
21
22
23
24
25
26
27
28
29
30
31
32
33
34
35
36
37
38
39
40
41
42
43
40
45
49
50
51
52
53
55
50

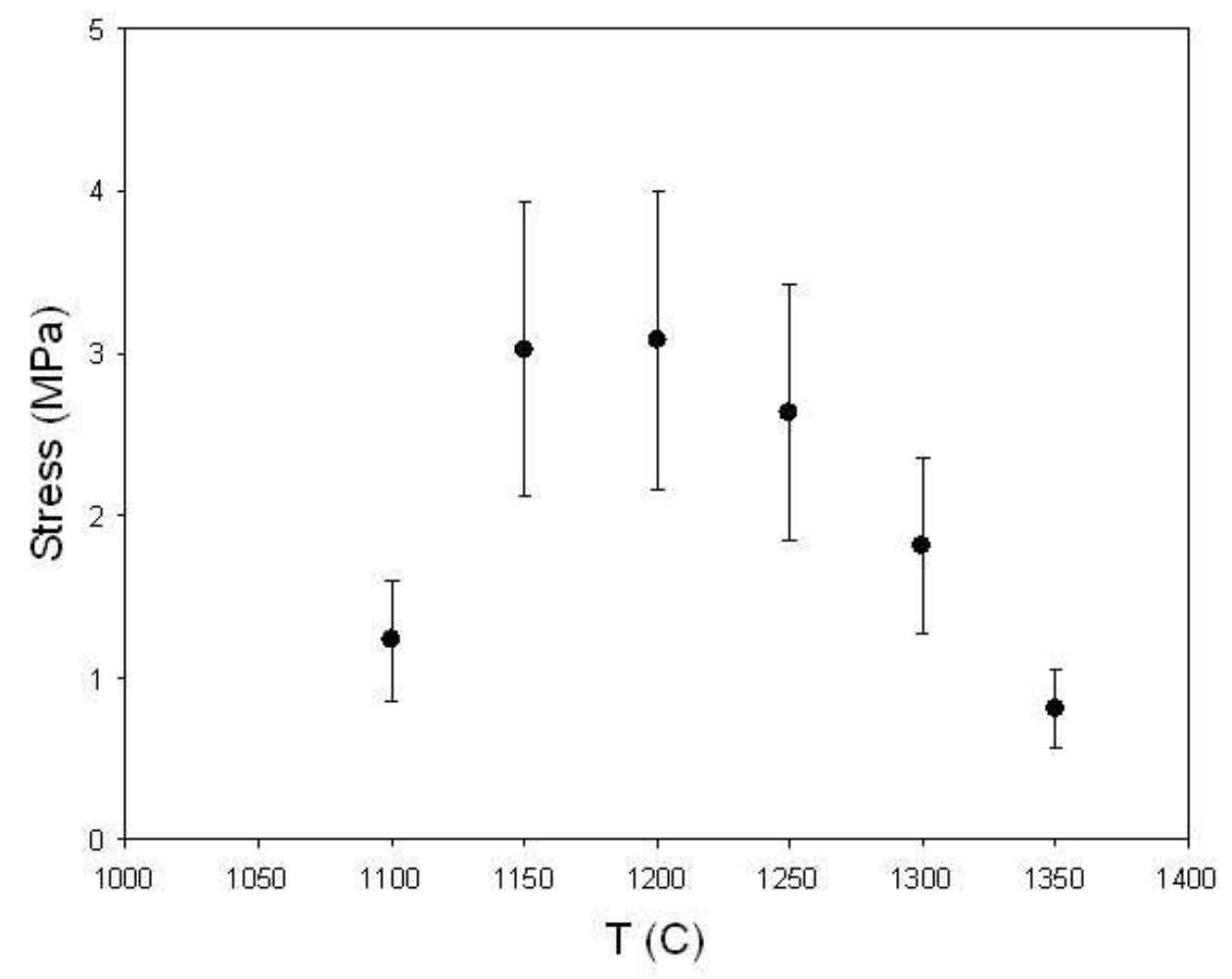

Figure 10

$212 \times 172 \mathrm{~mm}(72 \times 72 \mathrm{DPI})$

Journal of the American Ceramic Society 


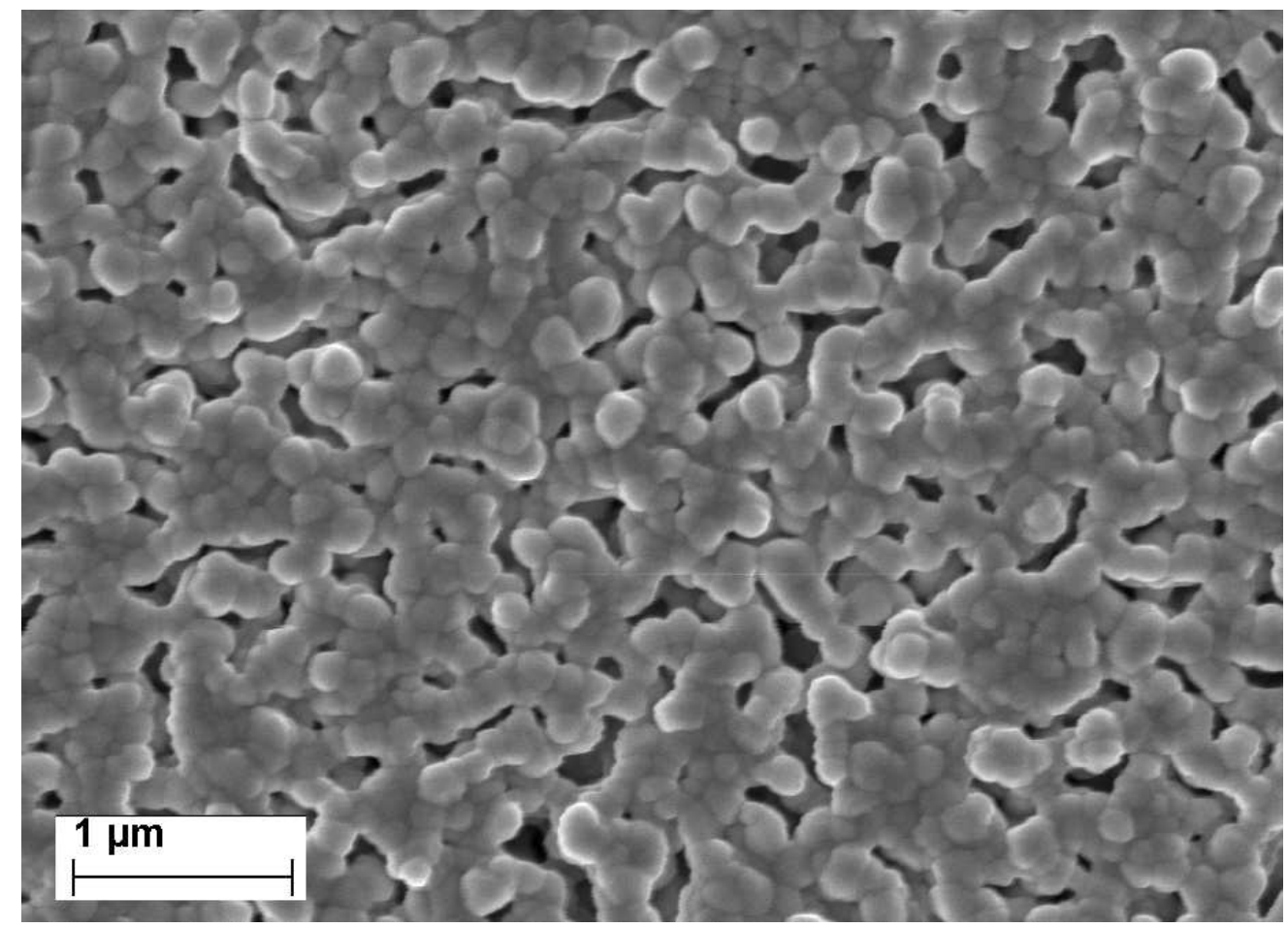

Figure 11a Secondary electron micrograph of the top surface of constrained 3YSZ film after sintering for $1 \mathrm{~h}$ at $1200^{\circ} \mathrm{C}$ $325 \times 234 \mathrm{~mm}(72 \times 72 \mathrm{DPI})$ 


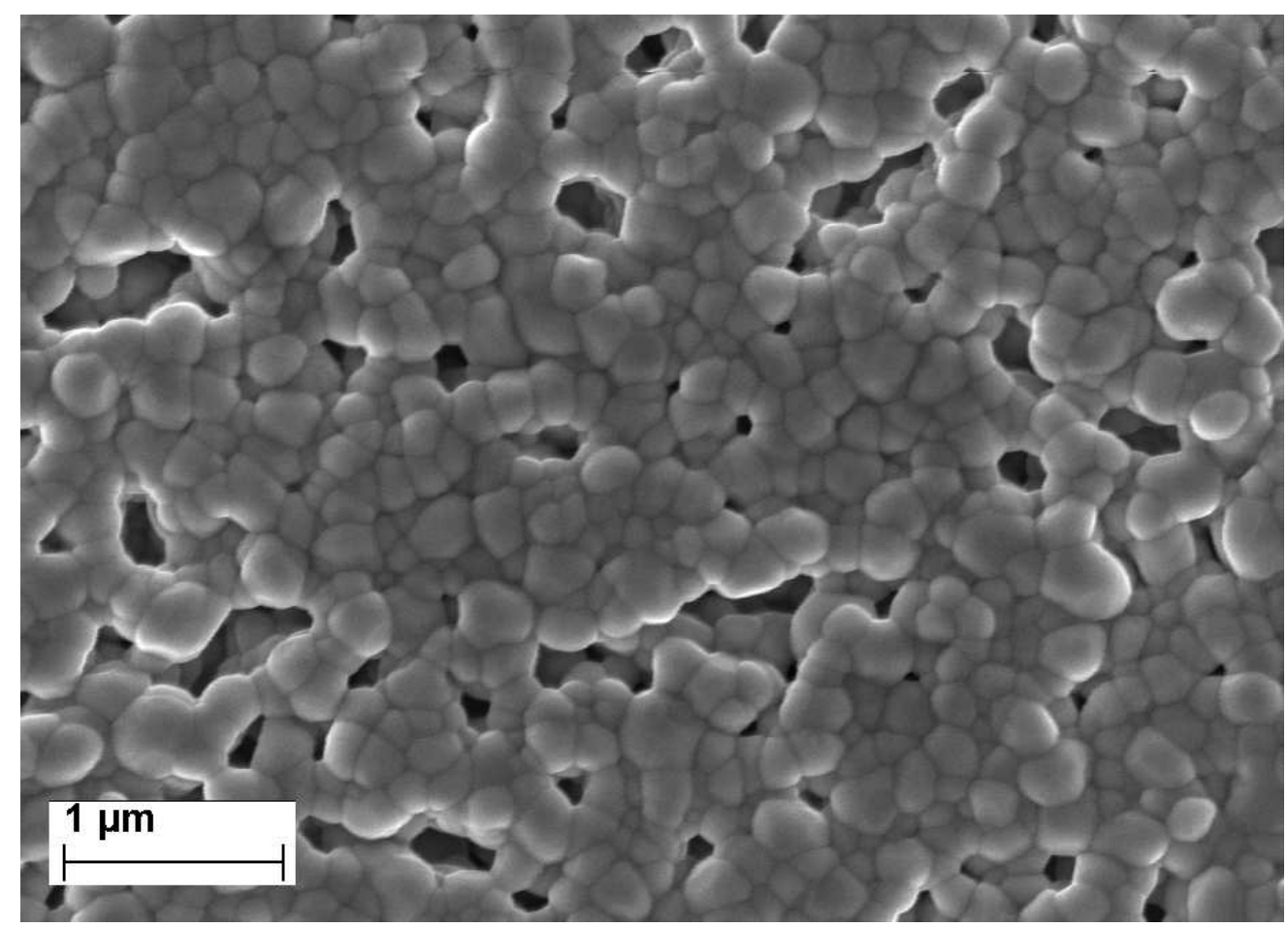

Figure 11b Secondary electron micrograph of the top surface of constrained 3YSZ film after sintering for $1 \mathrm{~h}$ at $1300^{\circ} \mathrm{C}$ $325 \times 233 \mathrm{~mm}(72 \times 72$ DPI $)$ 